Douglas a soft sausage-shaped or ovoid tumor, which is the pregnant tube.

4. The hospital type. This includes the neglected cases of the other types, and is, perhaps, the type most commonly met with by us in hospital practice. The early history is apt to be one of pelvic pain, abnormal menstruation, perhaps of a miscarriage or of small recurrent hemorrhages. Whatever it was at first, she is now evidently a decidedly sick woman, and is elearly growing worse. Fever, pelvic tumor (often of pretty large size) which may be so hard as to simulate a fibroid, or so soft that it evidently contains fluid (pus or blood), pain and tenderness, are the present symptoms. Diagnosis must usually depend almost wholly on the history, and, alas, is often impossible before operation. But though eorrect preoperative diagnosis may be impossible, the treatment is rarely in doubt, and rarely fails to clear up the case and result happily for the patient.

When a normal uterine pregnancy is associated with a tubal pregnancy, a diagnosis is highly improbable. A bilateral tubal pregnancy is also of such infrequent occurrence that it is almost invariably overlooked. The same is true of: the interstititial variety of tubal pregnancy, or pregnancy in a rudimentary horn, in one horn of a bicormuate, or in one side of a septate uterus. 'That all of these curios do occur I can assert positively from my own experience. Perhaps, at our hundredth meeting, some one will be able to give explicit directions for the differential diagnosis of each.

\section{ISXTRAUTERINE PREGNANCY.*}

By Raiph II. Seritg, M.I., Springifiedd, Mass.

Becuuse diagnosis is, in the last analysis, the most essential factor in medical practice is probably the reason why the eonsideration of cetopic gestation becomes one of the most fascinating problems with which the surgeon has to deal.

It has been most interesting to observe the development of knowledge on this subject, as many of us in our own professional experience have been able to do, from the extrauterine pregnancy as it was known twenty-five years ago, to the condition as it is known today. A quarter of a century ago a woman who bled to death from a ruptured, impregnated fallopian tube presented sufficient evidence to warrant the diagnosis of ectopie pregnancy.

Frequent opening of the abdomen for conditions of lesser gravity revealed many a mistaken diagnosis, and not a few diagnoses of pyo-salpinx and appendicitis were changed to extrauterine prognancy. Even at the present time it can probably be truthfully stated that more crrors are made in the diagnosis of ectopic gestation than in any other abdominal lesion.

To follow the preserihed and accepted and al-

* Reul at the inaugural meeting of the New England Surgical Society, Boston, Oct. B, 1016. together proper order of things in the eonsideration of medical subjects, however, the eausation of this condition must be first considered.

It is obvious that there must be some pathological change which affects the fallopian tube in some way so as to prevent the free passage of the ovum into the uterus. Previous pelvic inflammatory disturbances, ovarian, tubal and uterine tumor's may be considered as causative factors in about $60 \%$ of the cases (Graham). The other $40 \%$ show no particular abnormality. It is even stated (American 'T'ext Book of Gynecology) that in some eases of: ectopic gestation the mieroseope has diselosed no deviation from the normal in the epithelium of the tube. When we take into consideration the very large numher of minor as well as major abnormalities that are found in the daily routine of: pelvie surgery, it inclines one to hesitate in declaring with much positiveness that these abnormalities are to be held responsible for the failure of the ovum to reach the uterus. Until more light is cast upon it the actiology of ectopic gestation must continue to be shrouded in uneertainty.

The pathology of this eondition is, however, much more readily understood. As the ovim develops, the wall of the tube becomes gradually thimned by the growth of the villi into its surface so that usually in the early stages rupture oecurs, or less commonly the ovum escapes, or partially escapes from the distal end of the tube; or, in some instances, as we are informed, when it is located near the uterus the ovum enters that organ.

When the tube ruptures, the ovirm may or may not enter the abdominal eavity. If it does, conditions may be such that the placenta attaching itself to eontignous structures develops its eirculation from them and allows the foetus to live and rome to term. 'Two such eases I have seen, one of a brother practitioner and one of my own. They both died. My case was correctly diagnosticated by the family physician in a country town by palpation and the diseovery that the uterus was small and only four inches deep. In this ease the woman had felt motion until four days previous to operation. A dead child was found, a male, weighing $61 / 2$ pounds, lying in its membrane in the abdominal eavity. The placenta was attached all over the lower abdomen and pelvis in such a way that it was impossible to remove it safely. The membranes were stitched to the abdominal wall and the cavity packed. Sixtecn days later she died of sepsis. This was twelve years ago. I wonder if with the constantly increasing improvement in abdominal work we would not today rather face the somewhat desperate procedure of removing the attached placenta than the likelihood of sepsis developing during the sloughing out of the placenta.

Haemorrhage accompanies the rupture of the tube, and therein lies the essential element in the pathology of extranterine pregnancy. It is 
likewise the most important factor in the diagnosis, prognosis and treatment as well. It may be so slight as to cause practically no symptoms, or it may be so severe as to cause instant death.

The symptoms of extrauterine pregnancy up to the time rupture or tubal abortion oceurs are so trivial that it must be very rare that a diagnosis has been made in that stage of the disease. No instance of it has come to my knowledge.

When rupture does oceur, the haemorrhage may be so slight as to cause little disturbanee. 'There is pain, mild or severe. A not constant, but very significant feature, is pain deep in the pelvis, often in the restum, due to blood in Douglas's eul-de-sac. 'The more hamorrhage, the more pain. 'lhe most characteristic symptom is the slight, dark, bloody vaginal discharge which oecurs, ustally in from five to six weeks after the last menstrual period.

On the death of the embryo the uterine deeidua loosens and may eome away intact, but more often it loosens in shreds. This gives rise to this external haemorrhage, which nust never be disregarded in arriving at a diagnosis of tubal pregnancy.

My experience has led me to the conclusion that the diagnosis of ectopic gestation may be confidently made on the presence of this occurence accompanied by pain. This is well illustrated by a recent case: A woman was taken with a moderately severe pelvic pain, accompanied by a dark vaginal discharge. She had gone ten days over her menstrual period. On getting this history, I said to the nurse: "This is extrauterine pregnancy." On examination, a rounded, symmetrical mass was found which was apparently the uterus enlarged to about the size it would be if two months pregnant. Diagnosis from physical examination, pregnancy with attempt at miscarriage. After a delay of a couple of days, during which the symptoms subsided, an ether examination disclosed a uterus enlarged by what was apparently a fibroid growth. Opening the abdomen a ruptured fallopian tube was found, plastered onto the top of the uterus. If I had stuck to my diagnosis made from the history, I should have saved one of the many mistakes I have made in the diagnosis of this condition.

On the other hand, and curiously enough while narrating the above case, I was interrupted to see a woman, who, five weeks after a normal menstrual period, had a scanty, bloody vaginal discharge, with moderate pain. She thought she was pregnant and had even attempted to induce an abortion upon herself. The bloody discharge was not as dark in color as is ordinarily found in extrauterine pregnancy. Examination showed only an enlarged, somewhat tender retroverted uterus. The diagnosis of ectopic gestation was made, only to be proved wrong in a few moments by discovering on abdominal section that the patient's diagnosis of pregnancy was correct. In spite of this case, in which perhaps the error was due to disregarding the too bright color of the vaginal discharge, the diagnosis must be allowed to depend largely upon the history of the patient.

Some years ago a nurse was brought to the hospital with the characteristic story of six weeks' delayed menstruation, scanty, dark, bloody discharge and pain. She stoutly denied the possibility of pregnancy; but the diagnosis seemed clear, and a ruptured impregnated tube wials found.

Several of my eases have had flowing to a considerable extent, and have been curetted on the supposition that an abortion had taken place. Last winter a woman in such a condition was curetted by a friend of mine. He discovered at the time what he considered to be a small ovarian tumor, but not being an abdominal surgeon, did not open the abdomen. I saw her three weeks later suffering severely with abdominal pain and eonsiderable general disturbance, with fever and accelerated pulse. The history of the case and the "ovarian tunor" made the diagnosis seem clear, and ectopic pregnancy was found.

I note one case which I curetted in 1903, and felt a mass in the left side, which was thought to be pyosalpinx. Two weeks later, to my chagrin, I found a ruptured, impregnated tube, with a large amount of blood clot.

In several of my early cases the diagnosis of pyo-salpinx, before operation, had to be changed to ectopic pregnancy at operation. This is not at all surprising, however, in cases that did not come to early operation, as was more frequently the case fifteen or twenty years ago. In those cases there was considerable secondary inflammatory action, with elevated temperature, accelerated pulse, abdominal distention and rigidity, and by vaginal examination a large, tender mass.

Occasionally one sees an inflammatory condition of such intensity as to present the picture of acute appendicitis, with general peritonitis.

I shall not forget the second case of extrauterine pregnancy which I operated upon. It was in 1896 that I was called 25 miles up into the country to see, in a farmhouse, an unmarried girl of 20, who on Monday was seized with a sudden pain in the right lower abdomen. On Tuesday she was up and about; on Thursday she drove five miles for a Thanksgiving dinner. That afternoon very severe pain in the right side developed. Her physician was called, and gave her morphia. She grew steadily worse, and on Sunday, six days from the onset of her trouble, I found her with a temperature of 103.8 , and a pulse of 140 , with abdomen greatly distended, rigid, and exquisitely tender. She was semi-conscious and gave one the impression that she would live but a few hours. She was also blanched. Inquiry brought out the fact that she was naturally pale and anemic. Almost against my judgment, I was persuaded by the mother to operate in the face of impending dis- 
solution. An incision over the appendix revealed the abdominal cavity filled with black blood clot. A median incision was made, and a ruptured tube removed. Large masses of clot were removed, the abdomen thoroughly washed out, and a drain inserted. A year later I was pleased to receive a newspaper clipping from the family physician announcing the engagement of Miss So-and-So to Mr. So-and-So.

The prognosis of ectopic gestation depends upon the treatment, and the treatment depends upon the diagnosis.

I find records of 49 cases of tubal pregnancy which I have operated upon. Four of these cases died. One was the full-term abdominal pregnancy already referred to; another was a woman operated upon twelve years ago for ovarian cyst-which she had-but in addition she had a ruptured tube, bound down behind the uterus with a mass of very dense adhesions. For some reason unknown she did not rally from the operation, and died the next day. The other two cases were women who were exsanguinated, and it is in this class of cases only that there is any occasion for discussion of the treatment of extrauterine pregnancy. My experience with these cases is not sufficient to warrant the drawing of authoritative conclusions. Nevertheless, I have been forced to the opinion that women exsanguinated from ruptured tubal pregnancy are not proper subjects for operation until the collapse attendant upon the hemorrhage and shock can be at least partly overcome.

Both of my fatal cases were in 1902. The first one was sent to the hospital three days after the occurrence of pain and collapse. She was markedly exsanguinated. The pulse was 140 , and scarcely perceptible. $\Lambda$ ruptured tube was removed, and with it a very large amount of blood clot. She did not rally from the operation, however, and died two days later.

A few months after this I was called up into the country to see a young woman who three days before had abdominal pain and bloody vaginal discharge. Three hours before I saw her, pain recurred. Her pulse was then 80 . I found her blanched and pulseless. Five hours after operation she died.

I have always felt that if operation had been delayed until these two women had recovered somewhat from the effects of internal hemorrhage, their lives might have been saved. This opinion is substantiated by two similar cases which were treated differently.

Ten hours after collapse I saw a woman in a farmhouse, apparently dying-blanched, pulseless, sweating, unconscious, and scarcely breathing. Various methods of resuscitation having proved of no avail, I expressed my sympathy to the family and left her with her physician. Three days later she had recovered sufficiently to be brought to the hospital. Although markedly affected with hematogenous jaundice, her gen- eral condition was good. She withstood the operation well and made a good recovery.

Last winter a woman was sent into my hospital service,-blanched, collapsed, and almost pulseless from ruptured ectopic pregnancy. Her blood pressure was 60 . Inability to procure a donor made transfusion impossible. The use of normal saline solution intravenously and sub. cutaneously, brought the blood pressure up to 100. At this point the operation was begun, the salt solution meanwhile being kept up. At the end of the operation the blood pressure was 110 , and a good recovery followed.

Extrauterine pregnancy is, perhaps, as satisfactory a condition as the surgeon has to deal with, presenting as it does, the very nice problem of diagnosis, never lacking in interest, and offering an opportunity for immediate and practically certain relief without annoying sequelae and disastrous recurrences frequently found in other classes of cases.

\section{DISCUSSION.}

Dr. Frenerick 13. Swret, Springfield: My experience with the condition under discussion has brought to me two very distinct impressions.

First: The difficulty, the grent difficulty, of diagnosis before rupture.

Second: The low mortality of this condition as managed in recent years, considering its gravity.

These impressions are strengthened by the papers just read. It seems to me that one reason we seldom make correct diagnosis is because few women seek advice before rupturo has occurred. They think the early symptoms of little importance, and fail to consult their medical man or surgeon. $\Lambda$ side from lack of opportunity, however, the problem itself is a difficult one, as Dr. Seelye's frank recital of his experience proves. For often when we think it is extrauterine pregnancy, it is not, and vice versa. In the fow cases in which I have made correct diagnosis before rupture, I have felt that luck rather than wisdom was the determining factor.

Finally as to mortality: This is lower than in almost any other abdominal emergency and that, whether operation be done at once, delayed for cause, or on occasion withheld altogether.

There is one point concerning these cases which neither speaker brought out, namely, the comparative frequency of a repetition of the condition in the other tube. My operative records show several such cases.

Dr. Michael F. Fallon, Worcester: Extrauterine pregnancy is not always in the tube, and it fell to my lot sometime ago to find an ovarian pregnancy. The pregnancy occupied the ovarian tissue the size of an adult's little finger tip. The specimen was sent to the Harvard Medical School. At the time of operation there was a quantity of blood in the pelvis, and the remarkable thing was that thero was a constant dripping of blood from this pregnant area in the ovary.

Dr. J. M. GlLE, Hanover: Doubtless most oases of extrauterine pregnancy should bo operated on as soon as diagnosis is made. When, however, the patient is severely exsanguinated, the additional shock of immediate operation may, I believe, prove fatal, whereas, with time given to allow them to rally, they may be operated on with safety. 
In my own experience, the patient rarely actually' bleeds to death from this condition, for, despite any theory conceruing it, the blood actually does clot about the seat of rupture, and as the pressure diminishes, this clot becomes firm mough entirely to stop the hemorrhage, and in this condition, with the use of saline stimulation, the patient may more safoly be allowed to wait for a period of several, and even many hours, than to be operated on at once. In the cuses to which we are ealled, often many hours after the rujuture oceurs, I believe the bleeding will either have stopued or the patient will have died before aid arrives.

Dr. Pene Jonnson, Beverly. I am inclined to agree with the position Dr. Gile takes, because the only caso of extrauterine pregnancy I have lost was one upon whom I operated while in an exsanguinated condition. Personally I feel very strongly that the only thing to do in the extremely exsanguinated cases is to leave them absolutely alone temporarily and give the vessels a chance to close, postponing operation intil a more favorable time.

Dr. Homm Gack. Worcester: I should like to ret into this discussion to emphasize a single point. Shortly after I had begun the practice of medicine, I remember very well being asked to see the wife of a friend, who was also a friend of Dr. Maurice $H$. Richardson.

She had had in the night a sudden internal hemorrhage from the rupture of a tubal pregnancy. It was decided to wateh and wait. In spite of a condition of extreme shook, which was stendily growing worse, we waited for Dr. Richardson. Four of us stood around and watched that woman dic ten hours after the rupture. Today, I should consider such waiting indefensible.

We have now the Kimpton method of immediate transfusion, or, if these tubes are not at hand, we have the method used so successfully at Mt. Sinai Hospital, New York, of drawing the blood into a glass syringe and mixing it with $2 \%$ citrate solution, which can be always available.

Tmmediate operation and immediate transfusion, whon the condition of the patient demands it, are tho things to do.

Dr. Scmuer. J. Mix'ier: I want to got into this too. I have seen patients die from waiting. You cannot toll which one is going to die. That case that Dr. Gage speaks of, I remember very well. You can't tell which way they aro going to go. You can do better if you have time for transfusion, it not, get in salt solution; get the tube tied off. Do something and do it quick, and you will save moro people than you will kill.

Now there is one thing that has not been said: the septic cases-cases that-have been neglected. They gret septic abscesses in the pelvis; they die. You should make a holo in the top of the vagina; let the blood and pus, and sometimes even a brokendown fetus, come out. Put in a big enough tube and the patient will get well.

In Chadwick's cases of abdominal pregnancy with death of the fetus, supposed at the time to have been a rupture of the uterus, he removed an unchanged dead baby from the abdominal cavity some years later, the woman being pregnant at the time. I remember this crise well, for I had the honor of assisting at the operation.

Dr. W. P. Graves, Boston: It is important in a discussion of this subject to take into consideration tho pathological anatomy of tubal pregnancy.
There are in these cases two capsules, the outer one being composed of the thinned-out wall of the tube, whilo the inner capsule is the surrounding membrane of the fetal tissue. If only the inner capsule ruptures, the blood may ooze out slowly, and eventually clot, forming a tubal hematocele. I with recovery after the blood begins to clot.

If the outer capsule breaks, the blood pours directly into the peritoncal cavity unchecked. The latter condition is that in which the patient blceds to death culess there is surgical intervention. It is sometimes impossible to tell from the symptoms of a given case which condition is represented, and it, therefore, seems to me sensible to interfere and stop the hemorrhage as soon as possible. (Demonstration on blackboard.)

Dr. Garky DeN. Hough (closing): $\Lambda \mathrm{s}$ far as the diagnosis of tubal pregnancy is eoncerned, I use the seheme that I presented here today, and have used it for the last ten years. I think that in a fair majority of cases diagnosis ean be made, and that the cases in which diagnosis is really difficult are the neglected cases of people who come to the hospital so long after the original thing has huppencd that they cannot give you an intelligent history.

I agree with those who believe that cases with rupture should be operated upon at once. It is a case of blood pressure. If the blood pressure is too low, the patient cannot stand it. You can often get a forceps into the abdomen through a small incision in the vaginal vault and stop the bleeding. This will give control of the bleeding long enough for a transfusion to be done, and then one can safely proceed to whatever radical operation is necessary. I am very glad our papers have brought out so much disoussion.

Dr. Ralph H. Seerye (closing): This discussion has been very interesting. I cannot agree with the suggestion made by Dr. Hough, that the bleeding point may be reached by a clamp through the vaginal vault. It seems to me that one should go into the abdomen and see what he is doing.

The position I take in regard to operating on exsanguinated cases-I refer to the extreme cases of women who are pulsoless, blanched and sweatingis that these women, if operated upon immediately, are in more danger than if you let them wait. They are bled out, and the hemorrhage will in most cases stop spontaneously. Do everything possible, by means of salt solution, blood transfusion and stimulation, to improve this condition. But do not operate until the patient begins to rally from her collapse. It is hard to sit by and not operate, with the patient in a condition of extreme collapse and perhaps still bleeding, but my experience makes me feel very strongly that it is the proper thing to do.

Dr. S. J. Mixten: Put them on the table; first give them salt solution or blood transfusion, then go ahead and operate.

This is the last of the papers, I believe. This has been an interesting meeting and the discussions have been good. It is a good thing to step on someone's toes occasionally and to have your own stepped on. I thank you for your attendance and support. This being the last of the literary part of the program, I, as presiding officer, have finished and I thank you very much. The meeting is adjourned. 